\title{
Knowledge of Breastfeeding and Fertility of Women in Southwest Nigeria
}

\author{
${ }^{1}$ Odu Bimbola Kemi, ${ }^{2}$ Ogunlade Joseph Olurotimi \\ ${ }^{1}$ Faculty of Education, University of Ado-Ekiti, Nigeria \\ ${ }^{2}$ Department of Educational Psychology, College of Education Ikere-Ekiti
}

\begin{abstract}
The study examined the knowledge of breastfeeding and fertility among women in South West Nigeria. The descriptive research design of the survey type was used for this study. The population for the study was made up of women with breastfeeding experience in South West Nigeria. The sample consists of 1250 women sampled from three states in South West Nigeria. Multistage sampling technique was used to select the sample. The research instrument used to collect data from the respondents was a self designed questionnaire titled Knowledge of Breastfeeding and Fertility Questionnaire $(K B F Q)$. The instrument was valid and reliable; it had a construct validity correlation coefficient of 0.74 and a reliability coefficient of 0.86 which was obtained at 0.05 level of significance. The study revealed that women are well informed about breastfeeding with a significant attention to regular and frequent exposure of their baby to sucking. This was seen to have a considerable effect on the fertility of women through the delay of ovulation lending to child spacing.
\end{abstract}

\section{Introduction}

World Health Organization [22] explains health as a state of complete physical, mental and social well-being of an individual. What, though determines the degree of that well-being? A modest house may be built using boards, nails, and corrugated iron, but the different parts are often supported by four Corner posts. Similarly, our health is shaped by well numerous influences, but are related to four corners influences. They are (1) behaviour (knowledge) (2) environment (3) medical care (4) biological makeup.

Just as you can strengthen your house by upgrading the quality of the posts, so you can better your health by improving the quality of these influencing factors. Of the four factors, your knowledge which is an antedote of our behaviour, mostly for the purpose of this paper is the one within your control changing it for the better can help.

Breastfeeding is the act of feeding the baby from the breast. According to WHO [9] Breastfeeding confers substantial health benefits on both mother and child. For the infant, the principal advantages of breast milk are nutritional and immunological. For the mother, breastfeeding encourages the involution of the uterus and thus the rapid return of uterine womb which helps the mother to regain her natural shape. It promotes an affectionate bond between mother and child. It is economical and it is convenient. (McNeily [9], Hatcher [5], Orubuloye [14].

Breastfeeding knowledge according to Foster [3] is a social phenomenon related to breastfeeding activities and attitude which are under the control of norms and standards of social practices and expectation, they constitute activities which provide support for the mothers' choice to breastfeeding based on the behaviour that is healthiest for her and her new born, giving rise to what is commonly referred to as exclusive breastfeeding and supplementary breastfeeding practice.

Several studies in the past also indicated a decline in breastfeeding practices in tropical African societies and that this decline is faster in urban than in rural area. Nag [11] in particular, associated the decline with changes in socioeconomic conditions especially women's education. Meanwhile breastfeeding has been observed to have direct effect on the fertility of the nursing mother, medical evidence indicated that lactation provides a degree of contraceptive protection through the inhibiting of the release of pituitary and ovarian hormones.

However, the contraceptive protection of breastfeeding may depend on the frequency and intensity of sucking which appears to be diminishing rapidly with time in Nigeria.

Existing literature on the effects of breastfeeding on fertility Orubuloye [15] and Babe 
[2] reported that medical evidence indicated that lactation provides a degree of contraceptive protection through the postpartum amenorrhea caused by the elevated prolatin level which inhibits the release of pituitary and ovarian hormones. The prolactin is responsible for the secretion of milk in the breast which produces delay in ovulation. Gray [4] explained further that this inhibitory effect of protection disrupts the carefully balanced release of pituitary and ovarian hormones required for the ovulation and the resumption of normal menstruation cycles. This process is referred to as Lactational Amenorrhea Method (LAM).

Simultaneously it provides safe and effective temporary child spacing. It may be used for up to six months postpartum during full or nearly full breastfeeding and amenorrhea has been shown in clinical trial to be $99 \%$ effective. The contraceptive protection of breastfeeding normally depends on frequency and intensity of breastfeeding normally depends on the frequency and intensity of sucking of the infants on the breast. Kiplely [8] describes such breastfeeding behaviour as the kind of nursing that most effectively spaces babies: nursing on cue, keeping baby close, providing all nourishment and liquids at the breast for the first five to eight months and nursing to comfort the baby.

All of these practices limit the nipple stimulation that suppresses ovulation. If breastfeeding is supplemented then the amount of the proclatin produced will be insufficient to delay ovulation. Lactational amenorrhea - the lack of period which breastfeeding mother experiences is an important part of the benefits of breastfeeding, in that the mother is able to recover from the birth of a baby, from the discomfort of a monthly period and she is unlikely to conceive a second baby quickly.

Literature confirmed that in tropical Africa, it is the intensive and prolonged breastfeeding practice that is responsible for the long inter-birth intervals that have been observed in these traditional societies and which had made fertility in these societies far below the biological maximum of $15.30 \%$ children per woman.

Orubuloye [15] confirmed that in some parts of Africa, breastfeeding is reinforced by the custom of child spacing. In the Yoruba context where marriage is almost universal, the extent of the use of contraception appears to be low, abortion is not allowed or practiced openly, the difference in fertility could be attributed to postpartum nonsusceptible periods. It is the breastfeeding practice that determines an ovulation or amenorrhea.
Another factor is the strength of the mother's desire for a healthy infant combined with her knowledge about the benefits of breastfeeding. If she believes breastfeeding benefits the child as the strongly desires a healthy child, she will be more likely to breastfeed. A second issue is a mother's understanding about the relationship between breastfeeding to her own health and fertility. It is believed that every woman possesses the ability to breastfeed her baby as asserted by the United Nations Children Fund [17] (UNICEF). In their explanation they opined that the experience may be strange, tingling and exciting but in matter of days, mother and baby will surely find a comfortable and enjoyable routine mutually beneficial to both.

However the following contradictions to women's health in a few cases have been agreed upon that exception be granted to breastfeeding: cases of HIV infections in mothers, some medical reasons where the mother is on drugs, cases of tuberculosis, psychoactive disorders, cases of diabetes mellitus, and others (UNICEF [17] and WHO [21] ). It is on record that breastfeeding is common in Nigeria, but the importance of breastfeeding as a mechanism in controlling fertility in South West seem to be low (Odu and Ogunlade, [12] ). Whereas, Adegbola [1] posited that the attitude of women to breastfeeding is affected by location; women in the rural areas have longer duration of breastfeeding than their contemporaries in urban areas. Kendal [7] also noticed that women in the urban have shorter duration of breastfeeding, which according to UNICEF [17], WHO [24], UNO [18], could be an attempt to improve the health condition of women where urban growth is a very recent phenomenon.

The inability of women to change their behaviour towards the improvement of breastfeeding practices to ensure the contraceptive effect is the major concern of the researcher. Observation reveals that the idea of women breastfeeding a child for 12 months is now seen as antisocial and primitive. If nursing mothers continue to reduce the incidence and quality of breastfeeding practice it may be dangerous and disastrous to the health of the mother and the child, also it may lead to short birth interval and have an adverse effect on the population.

To pilot the study one general question was raised and two hypotheses were generated.

1. What is the frequency of breastfeeding among women in south west Nigeria.

2. There is no significant relationship between frequent sucking and duration of Amenorrhea (Fertility). 
3. There is no significant relationship between women's knowledge of infant feeding and their intensity of breastfeeding.

\section{Methodology}

The study made use of descriptive design of the survey type. The population consisted of all the women in South West Nigeria. The sample consisted of 1250 women who were selected using stratified, purposive and simple random sampling techniques. The research instrument consisted of two sections, section A consists of social characteristic of respondents such as religion, sex of the children, educational qualifications, age, location of residence and some background information such as birth interval, resumption of menstruation. Section B consisted of twenty items on knowledge of breastfeeding and fertility. The research instrument was validated while the reliability of 0.86 was obtained using split half method of establishing reliability. Research assistants and the researchers administered the questionnaire. The data was analysed using frequency count, percentages to describe the data, chi-square $\left(\mathrm{X}^{2}\right)$ was used to test the hypothesis at 0.05 level of significance.

\section{Results}

At the end of the analysis, the results were presented in tables to highlight the major findings in line with the research question and hypothesis.

Question 1: What is the frequency of breastfeeding among women in South West Nigeria?

To answer the question, responses on items 15 and 16 of the questionnaire which depicted the frequency of breastfeeding during the day and night were use. The result is shown in Table 2.

The result of Table 1 reveal that $20(1.6 \%)$ of the total sample breastfeed their babies ranging from 1-5 times during the day, 318 (25.4\%) breastfeed between 6 and 10 times, 125(10\% between 11 and 15 times, $284(22.7 \%)$ breastfeed between 16 and 20 times while 503(40.2\%) were not certain about the frequency of breastfeeding during the day time.
Responses on frequency of breastfeeding during the night day women in South West Nigeria showed that $539(43.1 \%)$ of the subjects put their babies to breastmilk between 1 and 5 times, 107 $(8.6 \%)$ breastfeed between 6 and 10 times in the night, $385(30.8 \%)$ had their frequency to breastfeeding ranging from 11 to 15 times, 123 $(9.8 \%)$ breastfeed between 16 and 20times in the night while only $96(7.7 \%$ ) could not ascertain their frequency of breastfeeding activities took place during the night compared to day time as frequency of breastfeeding increased in the night. This is so because mothers go to work during the day.

\section{Hypotheses}

1. There is no significant relationship between frequent sucking and duration of Amenorrhea (Child Spacing).

2. There is no significant relationship between women's knowledge of infant feeding and their intensity of breastfeeding.

\section{Hypothesis 1}

There is no significant relationship between frequency of sucking and duration of amenorrhea (Fertility)

To analyse the hypothesis, items on frequency of sucking (day and night) were cross tabulated with duration of amenorrhea. The result of chisquare is presented in Table 2.

Table 2 shows the relationship between frequency of sucking and duration of amenorrhea. The null hypothesis is rejected since X2cal (150.912, 109. 536, $\mathrm{P}<0.05)$

Therefore, there is a significant relationship between frequency of sucking and duration of Amenorrhea (Fertility). The result also reveals that duration of amenorrhea increases with increase in the frequency of sucking meaning that breastfeeding affect the fertility of women e.g 81 out of 125 respondents who breastfeed their babies between 11 and 15 times during the day resume menstruation after 7 months. Similarly, 204 out of 284 respondents who breastfeed their babies 16-20 times during the day times resume menstruation after 7 months of delivery. 
Table 1. Frequency of Breastfeeding behaviour among Women in South West Nigeria

\begin{tabular}{|l|l|l|l|}
\hline Period & Frequency of Breastfeeding & Frequency & Percentage \\
\hline Day & Not Sure & 503 & 40.2 \\
\hline & About 1-5 times & 20 & 1.6 \\
\hline & About 6-10 times & 318 & 25.4 \\
\hline & About 11-15 times & 125 & 10.0 \\
\hline & About 16-20 times & 284 & 22.7 \\
\hline Night & Not Sure & 96 & 7.7 \\
\hline & About 1-5times & 539 & 43.1 \\
\hline & About 6-10 times & 107 & 8.6 \\
\hline & About 11-15 times & 385 & 30.8 \\
\hline & About 16-20 times & 123 & 9.8 \\
\hline
\end{tabular}

Table 2. Chi-square $\left(\mathrm{x}^{2}\right)$ Analysis shoeing frequency of sucking and duration of Amenorrhea

\begin{tabular}{|c|c|c|c|c|c|c|c|c|}
\hline & & & & Duration C & nenorrhea & & & \\
\hline \multirow{7}{*}{ 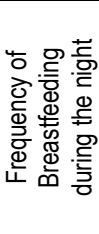 } & & Immediately after Birth & $1-3$ & $4-6$ & 7months+ & Total & $\mathrm{X}^{2} \mathrm{cal}$ & $\mathrm{X}^{2}-\mathrm{Tab}$ \\
\hline & Not Sure & $5(6.5)$ & $8(12.1)$ & $43(28)$ & $40(49)$ & $96(96)$ & \multirow{6}{*}{109.536} & \multirow{12}{*}{100} \\
\hline & $1-5$ times & $26(36.7)$ & $84 .(67.7)$ & $205(157.3)$ & $224(277.2)$ & $539(539)$ & & \\
\hline & $6-10$ times & $5(7.2)$ & 15(13.4) & $17(31.2)$ & $70(55)$ & 107(107) & & \\
\hline & $11-15$ times & $40(26.2)$ & $29(48.4)$ & $63(112.4)$ & 253(198) & $385(385)$ & & \\
\hline & $16-20$ times & $9(8.36)$ & $21(15.5)$ & $37(35.9)$ & $56(63.3)$ & 123(123) & & \\
\hline & Total & $85(85)$ & $157(157)$ & $365(365)$ & $643(643)$ & $1250(1250)$ & & \\
\hline \multirow{6}{*}{ 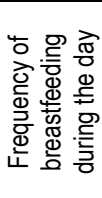 } & Not Sure & $42(34.2)$ & $71(63.2)$ & 134(146.9) & $256(258.7)$ & $503(503)$ & \multirow{6}{*}{150.912} & \\
\hline & $1-5$ times & $2(1.36)$ & $6(2.5)$ & $4(5.84)$ & $8(10.3)$ & $20(20)$ & & \\
\hline & $6-10$ times & $18(21.6)$ & $50(39.9)$ & $156(92.9)$ & $94(165.6)$ & $318(318)$ & & \\
\hline & $11-15$ times & $4(8.5)$ & $6(15.7)$ & $34(36.5)$ & $81(64.3)$ & $125(125)$ & & \\
\hline & $16-20$ & 19(19.3) & $24(35.7)$ & $37(82.9)$ & $204(146.1)$ & $284(284)$ & & \\
\hline & Total & $85(6.8)$ & $157(12.6)$ & $365(29.2)$ & $643(51.4)$ & $1250(100)$ & & \\
\hline
\end{tabular}

Table 3. Chi-squre $\left(\mathrm{X}^{2}\right)$ Analysis showing the relationship between knowledge of infant feeding and intensity of feeding

\begin{tabular}{|c|c|c|c|c|c|c|c|}
\hline & & \multicolumn{6}{|c|}{ Have Knowledge on breastfeeding } \\
\hline & & Yes & No & Total & $\mathrm{Df}$ & $\mathrm{X}^{2} \mathrm{cal}$ & $\mathrm{X}^{2}$ table \\
\hline \multirow{6}{*}{  } & About 5 minutes & $21(31.4)$ & $13(2.6)$ & $34(34)$ & \multirow[t]{6}{*}{4} & \multirow[t]{6}{*}{294.358} & \multirow[t]{6}{*}{7.81} \\
\hline & About 10 minutes & & & & & & \\
\hline & About 15 minutes & $294(286.9)$ & $17(24.1)$ & $311(311)$ & & & \\
\hline & About 20 minutes & $46(47)$ & $5(4)$ & $51(51)$ & & & \\
\hline & Until they shows satisfaction & $725(678.9)$ & $11(57.1)$ & $736(736)$ & & & \\
\hline & Total & 1153(1153) & $97(97)$ & & & & \\
\hline
\end{tabular}

\section{Hypotheses 2}

There is no significant relationship between women's knowledge of breastfeeding and their intensity of breastfeeding

Analysing the hypothesis involves cross tabulating intensity of breastfeeding of those who had knowledge of breastfeeding and those who do not. This was subjected to Chi-Square (X2) analysis. The result is presented in Table 3.

The chi-square $\left(\mathrm{X}^{2}\right)$ reveals that $\mathrm{X}^{2} \mathrm{Cal}$ (294.358) is greater than $X^{2}$ table (7.81) at 0.05 level of significance. The null hypothesis is rejected. Therefore, there is a significant relationship between women knowledge of infant feeding and their intensity of breastfeeding. 
Table 3 shows that 725 out of 736 respondents who had knowledge of infant feeding breastfeed their babies until satisfaction level is reached. In contrast, 51 out of 118 respondents who lack knowledge of infant feeding only breastfeed their babies for about 10 minutes.

\section{Discussion}

The result revealed that generally the frequency of breastfeeding is high; by implication it means that women in South West Nigeria put their babies to breast regularly. Probably because they have good knowledge of what breastfeeding can do to their health and that of their baby. This finding is consistent with the existing literature that breast milk is an excellent source of nutrition for the baby, and promotes an affectionate bond between mother and child. More so that it lengthens the interval between births. (Hatcher [5], Mc Neily [9], Orubuloye [14], Foster [3] and WHO [19]. This could further be explained that at group level woman believe that it is natural responsibility of woman to breastfeed their babies at individual level each woman might have developed positive self esteem that will enhance their intra and inter personal breastfeeding behavior. This view is supported by the submission of UNICEF and WHO [23] that breastfeeding experience may be strange tingling and exciting but in a day or two mothers and babies will surely find a comfortable and enjoyable routine mutually beneficial to both. The response of the subjects in the study to pattern of breastfeeding favorable to exclusive breastfeeding as the best means of feeding baby which support the argument of WHO[20], that human milk is ideal for the baby, cow milk for the calf and that breast milk is the best food for the child will ever have. All substitutes including cow milk, milk powder and cereal gruels are inferior.

Mores so, it is revealed that the frequency of breastfeeding is very high among women in south west Nigeria that is woman provide virtually all the baby's nutrition from the breast. On the average most of the breastfeeding activities were done in the night. This may not be so strange since most of our women are engaged in different work or activity during the day which might not allow them to breastfeed properly during the day. Therefore the night could be better time even when the mother is asleep some baby do suck till they slept off. But some were not sure about the number of times they do it in the night and during the days. This could mean that these set of woman are those who saw breastfeeding as a waste of time or making breast to sag or that breastfeeding should be relegated to the rural woman or those who cannot afford to buy commercial milk.

Furthermore the study sought to find out if a significant relationship exists between frequency of sucking and duration of Amenorrhea. The result revealed that there is a significant relationship between frequency of sucking and duration of Amenorrhea i.e if breastfeeding principle is strictly adhere to, it has a substantial effect on the fertility of women because it will lower the fertility of women. This result was supported by Kipley [8] that the contraceptive protection of breastfeeding normally depends on the frequency and intensity of sucking of the infant on the breast.

This process is called Lactational Amenorrhea Method (LAM) although this contraceptive protection of breastfeeding depends on the frequency and intensity of sucking of the infants on the breast. This is better explain through the description of Kipley [8] that such breastfeeding behaviour is the kind of nursing that most effectively space babies, nursing on cue, keeping baby close, providing all nourishing and liquids at the breast for the first six to eight months and nursing to comfort the baby, conclusively if the above routine is followed strictly breastfeeding can be used as interim family planning method and a means of spacing birth.

In hypothesis 2 it was discovered that there exist a significant relationship between knowledge of breastfeeding and intensity of breastfeeding among women. This could mean that the effort of agencies like World Alliance for Breastfeeding Action (WABA), Body Friendly Hospital Initiative (BFHI), World Health Organization (WHO), United International Children Education Emergency Fund (UNICEF) and the rest are worthwhile. In line with these findings, it becomes imperative that more effort must be geared towards encouraging women to see the importance of breastfeeding to the health of their baby and themselves.

Odumegwu [13] emphasized that giving information on reproductive attitudes and motivation may be helpful in understanding the factors that affects breastfeeding and fertility. It is very clear that women have a very high knowledge of basic concept of breastfeeding and 
child spacing. But many women are still very confused about the fact that breastfeeding can be a reliable contraceptive measure.

\section{Conclusion}

Considering the findings of the study, it was concluded that women have very good knowledge of breastfeeding. The frequency of breastfeeding their baby was high and this was observed to have effect on their fertility through the lengthening of their duration of amenorrhea. Meanwhile it was discovered that proper breastfeeding most especially exclusive breastfeeding will improve the health conditions of both the mother and the child. It was concluded therefore that positive attitude towards breastfeeding will constitute activities that will provide support for the mothers' choice to breastfeed effectively, to improve the duration of breastfeeding and as such health Practitioners Counsellors and other related agency should encourage women to breastfeed their babies.

\section{References}

[1]] Adegbola, A.S (1990) Breastfeeding and post partum abstinence in metropolitan Lagos.

[2] Babe C.F. (1997). Breastfeeding and birth interval in Burundi. Medicine Tropiale.

[3] Foster, M.S. (2006) Women's decision about breastfeeding and maternal employment. Journal of Marriage and the family 58, 239-251.

[4] Gray, R.H. Campbell, R. \& Apelo, S. (2002). The risk of ovulation during lactation. Lancet; 335, 25-29.

[5] Hatcher R.A. (1990) Contraceptive technology, New York; Living Publishers.

[6] Idu E.U (1988) Development and preliminary validation of an instrument for measuring attitude towards mathematics. An unpublished M.Ed. Thesis University Nigeria Usukka.

[7] Kendal, M. (1999). The World Fertility Survey current status and findings. Population report series (3) Baltimore, Maryland, JHUP inf. Programme July Pg. 32.

[8] Kippley, S.M (1999) Breastfeeding and natural child spacing. Cincinnati, OH: CCL.
[9] Mc neilly, A.S., (1991): "Relationship of feeding patterns, proclaction and resumption of ovulation post-partum" in G.I. Zatuchini, M.H. Labbok \& J. Sciarra (Eds), Research frontiers in fertility regulation. New York Herper and Row Hagerstown, New York. (Pp 102-126).

[10] Mooney, E.T. (2005) Health sequelae of breastfeeding for the mother. Clin Perinatol 26(2), 491-503.

[11] Nag (1993) The ultimate breastfeeding book of answers. Roseville, C.A: Prima Publishing.

[12] Odu B.K and Ogunlade J.O (2011) Breastfeeding behaviour among women in Nigeria. Proceedings of Canada International conference on Education.

[13] Odumegu (1995). The role of marital sexual abstinence in determining fertility: A study of the Yoruba of Nigeria' Population Studies, 31, 193-217.

[14] Orubuloye, I.O. (1979): "The significance of breastfeeding on fertility and mortality. Journal of Tropical Pediatric and Environmental Child Health.

[15] Orubuloye, I.O. (1979): Child spacing among rural Yoruba women of Ekiti and Ibadan Division in Nigeria. Report Presented at the Workshop on child spacing in tropical Africa. Traditional and change. Brussels, April.

[16] Orubuloye, I. O., (1982). Attitude as an interaction concept, social constraint distance as intervening variable between attitudes and actions. American sociological Review. 24, 153169.

[17] UNICEF (2002). The state of the world children, London Oxford University press.

[18] UNO (2004). Report on the state of the World Health Feeding Policy. HIV and Infant Feeding.

[19] WHO (2001). Breastfeeding counseling: a training course. General (unpublished Who Document).

[20] WHO (2004) Preliminary report of the WHO collaborative study on breastfeeding (MCH / 79. 3): Geneva. 
[21] WHO (2005) The World Health Report Make every mother and child count. A special report of WHO Geneva. WHO Global Data Bank on Breastfeeding. Geneva, World Health Organization.

[22] WHO (2008) "The relation of economic class and fertility: An analysis of some Indonesian data" Population Studies, _31 (1) 4357.

[23] WHO/UNICEF (2007) Factors influencing decision to breastfeeding. Journal of Advance Nursing. 369-468. 